\title{
Non genomic loss of function of tumor suppressors in CML: BCR-ABL promotes IKBa mediated p53 nuclear exclusion
}

\author{
Sabrina Crivellaro ${ }^{1}$, Cristina Panuzzo ${ }^{1}$, Giovanna Carrà ${ }^{1}$, Alessandro Volpengo ${ }^{1}$, \\ Francesca Crasto ${ }^{1}$, Enrico Gottardi ${ }^{1}$, Ubaldo Familiari ${ }^{2}$, Mauro Papotti $^{2}$, \\ Davide Torti ${ }^{1}$, Rocco Piazza ${ }^{3}$, Sara Redaelli ${ }^{3}$, Riccardo Taulli ${ }^{4}$, Angelo Guerrasio ${ }^{1}$, \\ Giuseppe Saglio ${ }^{1}$, Alessandro Morotti ${ }^{1}$ \\ ${ }^{1}$ Department of Clinical and Biological Sciences, University of Turin, Orbassano, Italy \\ ${ }^{2}$ Division of Pathology, Department of Oncology, University of Turin at St Luigi Hospital, Torino, Italy \\ ${ }^{3}$ Department of Health Sciences, University of Milano-Bicocca, Monza, Italy \\ ${ }^{4}$ Department of Oncology, University of Turin, Turin, Italy \\ Correspondence to: \\ Alessandro Morotti, e-mail: alessandro.morotti@unito.it \\ Keywords: NF-kB, IkBa, chronic myeloid leukemia, p53, tumor suppressor \\ Received: February 05, $2015 \quad$ Accepted: July 13, $2015 \quad$ Published: July 23, 2015
}

\section{ABSTRACT}

Tumor suppressor function can be modulated by subtle variation of expression levels, proper cellular compartmentalization and post-translational modifications, such as phosphorylation, acetylation and sumoylation. The non-genomic loss of function of tumor suppressors offers a challenging therapeutic opportunity. The reactivation of a tumor suppressor could indeed promote selective apoptosis of cancer cells without affecting normal cells. The identification of mechanisms that affect tumor suppressor functions is therefore essential. In this work, we show that BCR-ABL promotes the accumulation of the NFKBIA gene product, IKBa, in the cytosol through physical interaction and stabilization of the protein. Furthermore, BCR-ABL/IKBa complex acts as a scaffold protein favoring p53 nuclear exclusion. We therefore identify a novel BCR-ABL/IKBa/p53 network, whereby BCR-ABL functionally inactivates a key tumor suppressor.

\section{INTRODUCTION}

The involvement of tumor suppressors in cancer pathogenesis has been extensively revised over the last years. Originally, Knudson proposed that tumor suppressors play a role in tumorigenesis when both alleles are genetically impaired, one through point mutation and one through deletion [1]. Several data collected in non hereditary tumors and in murine models have clearly demonstrated that tumor suppressors' involvement in cancer is a much more complex process [2]. In particular, tumor suppressor function can be modulated by subtle variation in protein expression levels, proper cellular compartmentalization and post-translational modifications of the protein, such as phosphorylation, acetylation and sumoylation $[3,4]$. Chronic Myeloid Leukemia is a myeloproliferative disorder driven by the translocation $t(9 ; 22)$ which codes for the chimeric protein BCR-ABL [5-10]. Chronic Myeloid
Leukemia has always been considered as an unique disease because it was referred as a 'single hit' cancer [11]. This interpretation is supported by the observation that BCR$\mathrm{ABL}$ alone is sufficient to induce the rapid onset of a leukemic phenotype in several murine models, without the need of additional genetic lesions [12]. Furthermore, no tumor suppressors have been reported mutated or deleted in the chronic phase of the disease, strongly supporting this unique biological feature of CML pathogenesis compared to other cancers. The revised model of tumor suppressor role in cancer suggests that BCR-ABL-mediated leukemogenesis could be associated with functional non genomic loss of tumor suppressors [2]. In this respect, PP2A and PTEN have already been described as BCR-ABL inhibited tumor suppressors [13-18]. Here, we demonstrate that BCR-ABL promotes the formation of a ternary complex with I $\mathrm{I} B \alpha$ and p53 in the cytoplasm causing loss of p53 tumor suppressive nuclear pool. 


\section{RESULTS AND DISCUSSION}

While investigating the cellular compartmentalization of I $\mathrm{B} \alpha$ in $\mathrm{CML}$ formalin-fixed paraffin-embedded specimens, we observed that IкB $\alpha$ was highly expressed and predominantly retained into the cytosol of myeloid progenitor cells when compared to normal bone marrow cells (Figure 1A). Interestingly, erythroid precursors do

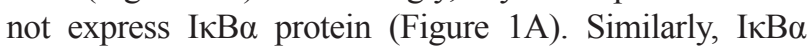
immunofluorescence on CML primary cells showed that I $\mathrm{B} \alpha \alpha$ is expressed predominantly in the cytoplasm (Figure 1B). To evaluate whether I $\kappa \mathrm{B} \alpha$ cellular compartmentalization is regulated by BCR-ABL, we expressed BCR-ABL and myctag-I $\mathrm{B} \alpha$ in HeLa cells. These cells were chosen because the large amount of cytoplasm allows to easily study cellular compartmentalization. As shown in Figure 1C, exogenous I $\kappa \mathrm{B} \alpha$ maintains a diffuse cellular compartmentalization in parental cell line, while expression of BCR-ABL promotes its nuclear exclusion. Notably, BCR-ABL and IкB $\alpha$ appeared also to co-localize (Figure 1C).

To better evaluate $\mathrm{I} \kappa \mathrm{B} \alpha$ localization in CML cell lines, IкB $\alpha$ immunofluorescence was performed in the CML cell lines BV173 and K562 and in the $\mathrm{Ba} / \mathrm{F} 3$ p210 BCR-ABL cells [19]. As shown in Figure $1 \mathrm{D}, \mathrm{I} \kappa \mathrm{B} \alpha$ is mostly expressed in the cytosol of the BV173 and K562 cell lines. Parental $\mathrm{Ba} / \mathrm{F} 3$ cells expressed IкB $\alpha$ both in the nucleus and in the cytosol, while $\mathrm{Ba} / \mathrm{F} 3$ p210 BCR-ABL are characterized by I $\mathrm{B} \alpha$ nuclear exclusion (Figure 1D). Similar results were observed in the BCR-ABL-32D cell line (data not shown). Notably, imatinib treatment does not significantly revert I $\kappa \mathrm{B} \alpha$ cellular localization (Figure 1D).

The observation that BCR-ABL and I $\mathrm{B} \alpha$ co-localized in transfected HeLa cells (Figure 1C) suggests that BCR$\mathrm{ABL}$ could interact with I $\kappa \mathrm{B} \alpha$. To test this hypothesis, HEK293T cells, upon transfection with BCR-ABL and IкB $\alpha$ vectors, were lysed and immunoprecipitation with myc-tag antibody was performed. As shown in Figure 2A, myctag-I $\mathrm{B} \alpha$ interacts with BCR-ABL. To map the BCR-ABL region that interacts with I $\mathrm{I} B \alpha$, we transiently transfected a BCR expressing vector together with myc-tag-I $\mathrm{B} \alpha$ in the HEK293T cell line. As shown in Figure 2A, BCR-ABL physically interacts with I $\kappa \mathrm{B} \alpha$ through the $\mathrm{BCR}$ portion of the chimeric protein. Notably, in the CML BV173 cell line, endogenous BCR-ABL interacts with endogenous I $\mathrm{I} B \alpha$ (Figure 2B). Due to the intrinsic nature of BCR-ABL as a tyrosine kinase, we next sought to investigate whether BCR-ABL promotes I $\mathrm{I} B \alpha$ tyrosine phosphorylation. To this aim, we performed a kinase assay with purified I $\mathrm{B} \alpha$ protein. As shown in Figure $2 \mathrm{C}$, I $\mathrm{KB} \alpha$ is not phosphorylated by purified $\mathrm{ABL}$ in vitro. Although $\mathrm{BCR}-\mathrm{ABL}$ does not directly phosphorylate I $\mathrm{B} \alpha$, we next explored whether BCR-ABL could indirectly tyrosine phosphorylate I $\mathrm{B} \alpha \alpha$ in vivo. We performed immunoprecipitation of myc-tag-IкB $\alpha$ in BCR-ABL positive cells, and we assessed the phosphotyrosine status of I $\mathrm{I} B \alpha$ by western immunoblot. I $\mathrm{B} \beta \alpha$ does not appear to be phosphorylated in vivo (data not shown).
This observation was also observed in the BV173 cell line, where immunoprecipitated IкB $\alpha$ does not hybridize with antiphosphotyrosine antibody (Figure 2B). All together these data suggest that I $\mathrm{IB} \alpha$ behaves as a scaffold protein in BCR-ABL signaling. Next, we investigated if BCR-ABL regulates IкB $\alpha$ expression and stability. To evaluate I $\mathrm{K} \mathrm{B} \alpha \mathrm{mRNA}$ expression levels, we performed qRT-PCR in BCR-ABL cell lines and primary CML cells. As shown in Figure 2D, there were no statistically significant differences between normal bone marrow and CML chronic phase, and between empty vector transfected cells and BCR-ABL ones, suggesting that I $\mathrm{I} B \alpha$ mRNA levels are not regulated by BCR-ABL at least at the steady state. We then performed a stability assay of $I \kappa B \alpha$ protein. HEK293T cells transfected with IкB $\alpha$ and with Bcr$A b l$ were incubated for 6 hours with the proteasome inhibitor MG-132. BCR-ABL appeared to regulate I $\mathrm{KB} \alpha$ protein stability at a post-translational level (Figure 2E).

$\mathrm{I} \kappa \mathrm{B} \alpha$ is mostly studied for its inhibitory activity toward NF- $\mathrm{kB}$, through the interaction with the NF- $\mathrm{kB}$ subunit p65 [21, 22]. I $\mathrm{I} B \alpha$ is a shuttling protein that moves into the nucleus, where it binds to active NF- $\mathrm{KB}$ and inhibits its transcriptional activity by removing it from the nucleus. NF- $\mathrm{KB}$ was extensively studied in the pathogenesis of CML [23-29]. IкB $\alpha$ was also shown to bind to $\mathrm{p} 53$, which shares with $\mathrm{p} 65 \mathrm{NF}-\mathrm{kB}$ a similar tridimensional structure [30-32]. TP53 is a tumor suppressor that is involved in several cellular processes, like senescence, cell cycle inhibition, apoptosis and DNA damage repair $[33,34]$. In CML, p53 was shown to be involved in the progression into the blast crisis, where almost $20 \%$ of the patients display mutated TP 53 , while TP 53 was never found mutated/deleted in the chronic phase of the disease [35]. Therefore, we hypothesized that IкB $\alpha$ could also promote $\mathrm{p} 53$ sequestration from the nucleus in CML. To this aim, we performed p53 immunofluorescence in primary CML cells. As shown in Figure 3A, p53 is retained into the cytosol of CML cells. Notably, nuclear excluded p53 was found to co-localize with IкB $\alpha$ in the cytoplasm (Figure 3B). To better validate these observations, we confirmed that IкB $\alpha$ co-immunoprecipitates with p53 in the presence of BCR$\mathrm{ABL}$ both in transfected cells and in primary CML bone marrow cells (Figure 3C).

All together these data indicate that BCR-ABL promotes cytoplasmic sequestration of the I $\mathrm{B} \alpha-\mathrm{p} 53$ complex. Previous works have clearly demonstrated that the I $\mathrm{BB} \alpha-\mathrm{p} 53$ complex is associated with the inhibition of p53 [30-32]. Notably, TNF $\alpha$ and the tyrosine kinase inhibitor staurosporine were shown to disrupt this complex, although the mechanism was unknown [30]. Our observations in primary CML samples and cell lines suggest that BCR-ABL promotes the sequestration and inactivation of p53 in the cytoplasm through the interaction with $\mathrm{I} \kappa \mathrm{B} \alpha$. The inactivation of $\mathrm{p} 53$ through sequestration and/or delocalization in the cytoplasm could harbor important therapeutic options. To test this hypothesis, we treated $\mathrm{Ba} / \mathrm{F} 3$ p210 BCR-ABL cells with imatinib and we assessed the cellular compartmentalization of p53. 
A

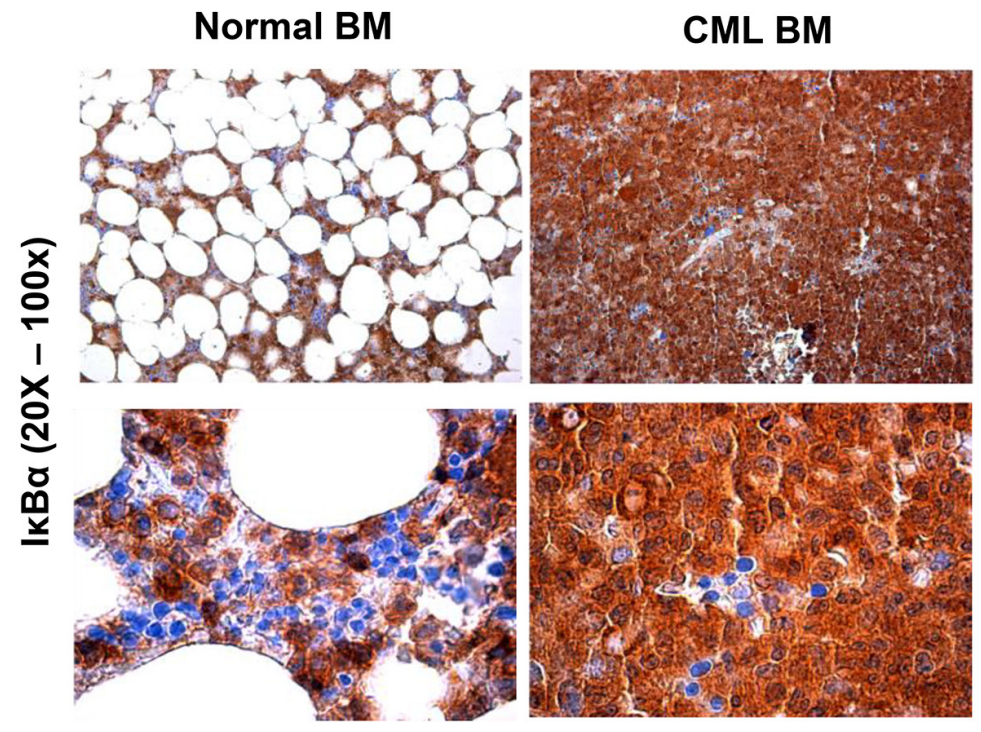

B

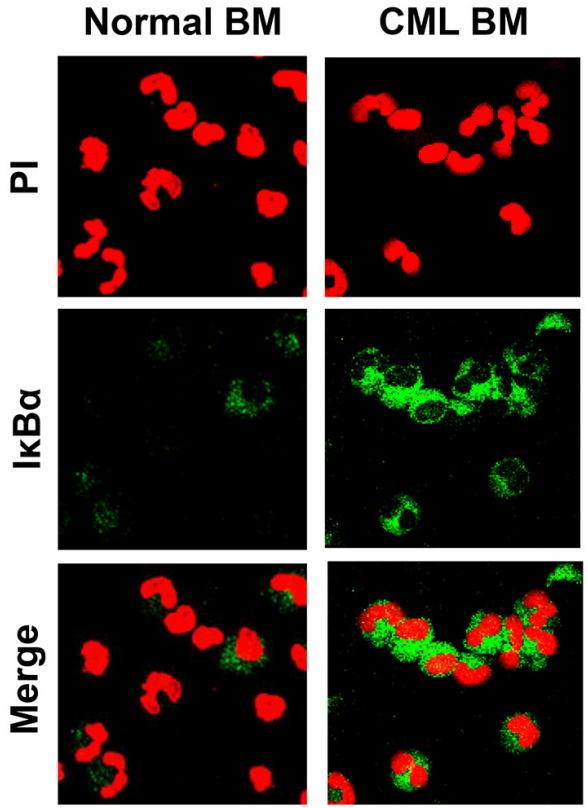

C

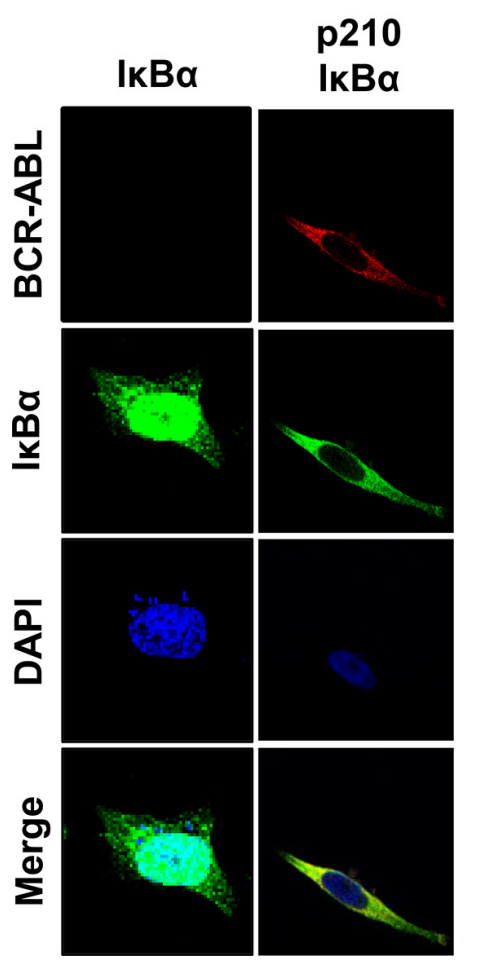

D

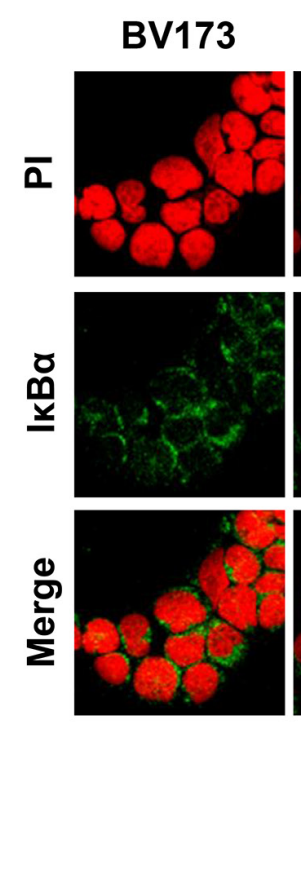

\section{$\mathrm{Ba} / \mathrm{F3}$}

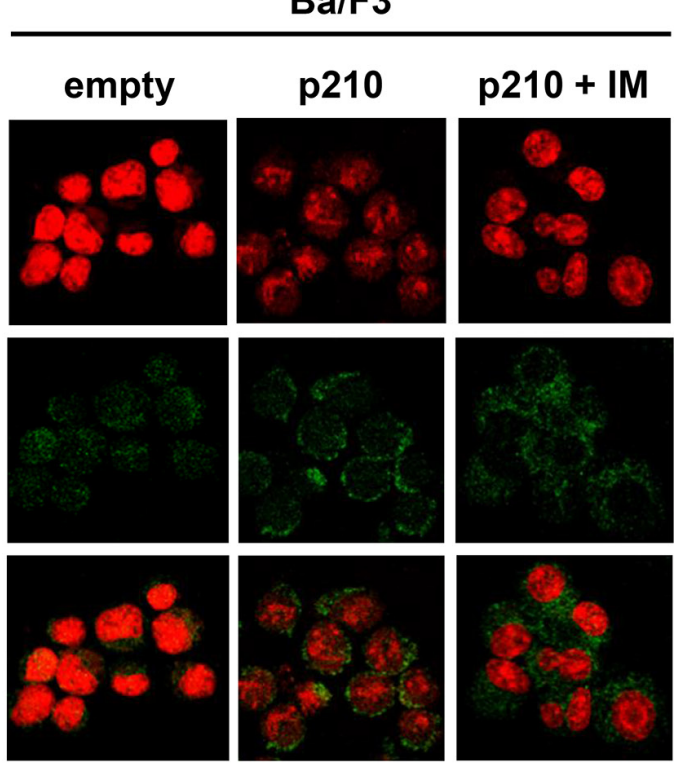

Figure 1: IкB $\boldsymbol{\alpha}$ in BCR-ABL positive cells. A. Representative immunohistochemistry using an anti-IкB $\alpha$ antibody performed on paraffin-embedded bone marrow from a representative CML or normal bone marrow. IHC was performed on 4 CML chronic phase samples with comparable results. B. Representative immunofluorescence on normal and CML primary bone marrow cells were performed to detect

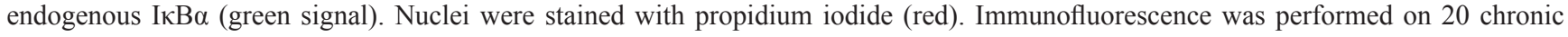
phase CML samples and 3 normal bone marrow samples with comparable results. C. HeLa cells were transfected with BCR-ABL and $\mathrm{I} \kappa \mathrm{B} \alpha$ plasmids. Immunofluorescence staining of I $\kappa \mathrm{B} \alpha$ (green) and BCR-ABL (red) was performed to detect I $\kappa \mathrm{B} \alpha$ localization. Nuclei were stained with DAPI. D. Immunofluorescence on the BV173 and K562 CML cell lines and on parental Ba/F3 and Ba/F3 p210 BCR-ABL cells was performed to detect I $\mathrm{B} \alpha$ (green signal). Nuclei were stained with propidium iodide (red). When indicated, cells were treated for 6 hours with $10 \mu \mathrm{M}$ of imatinib. 
A

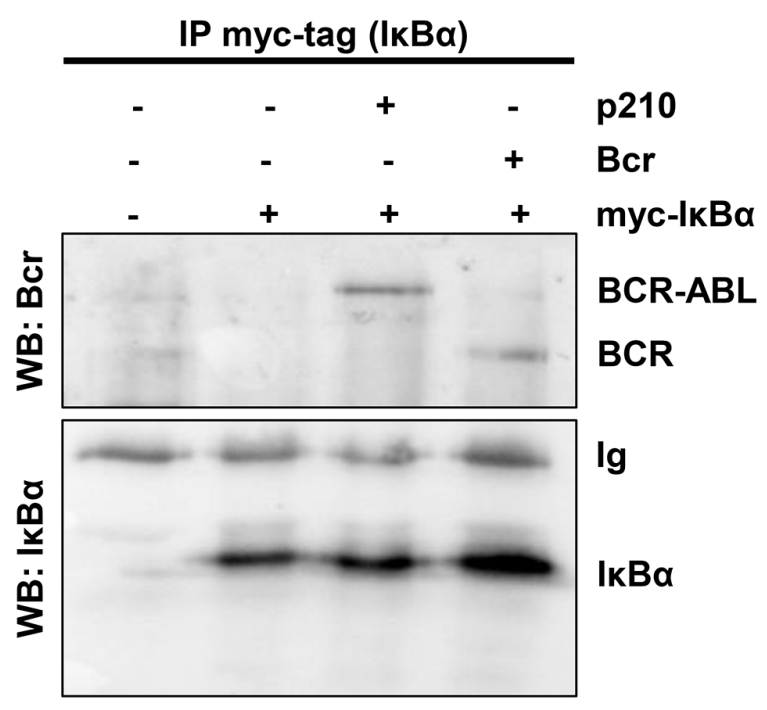

B

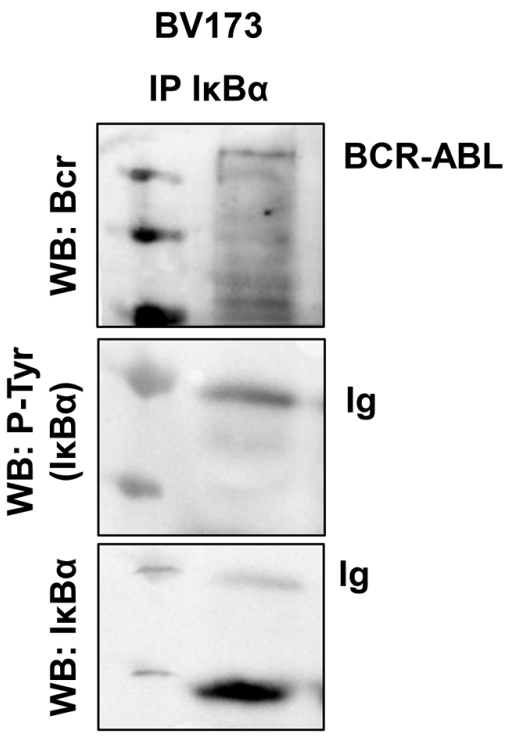

C

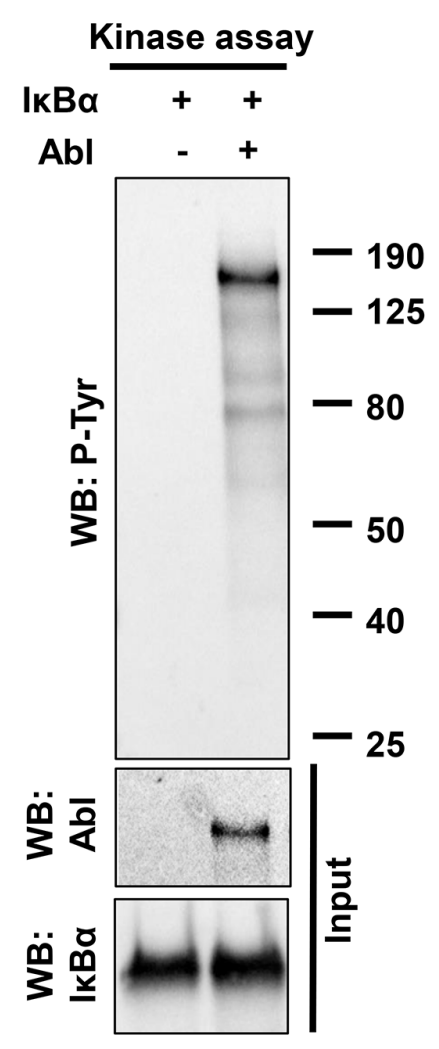

D
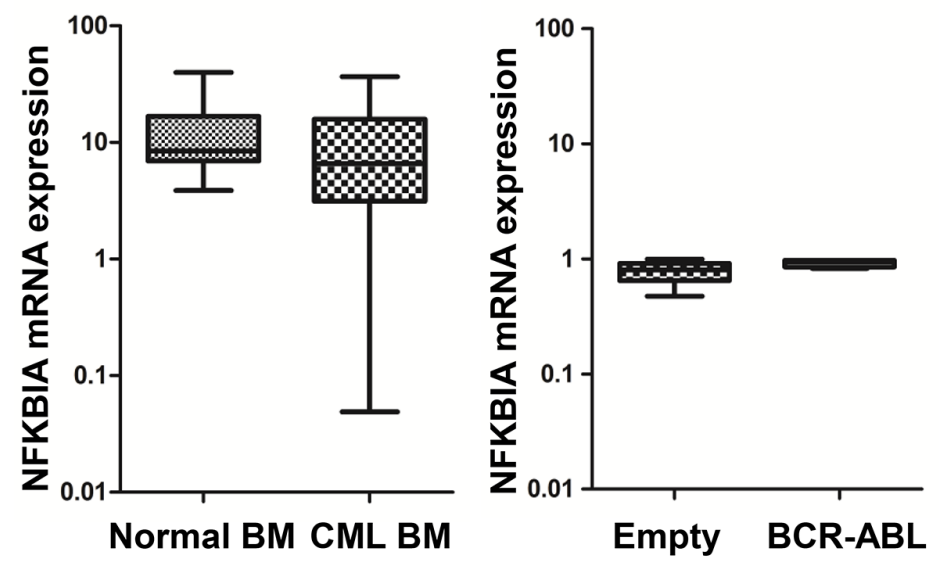

E

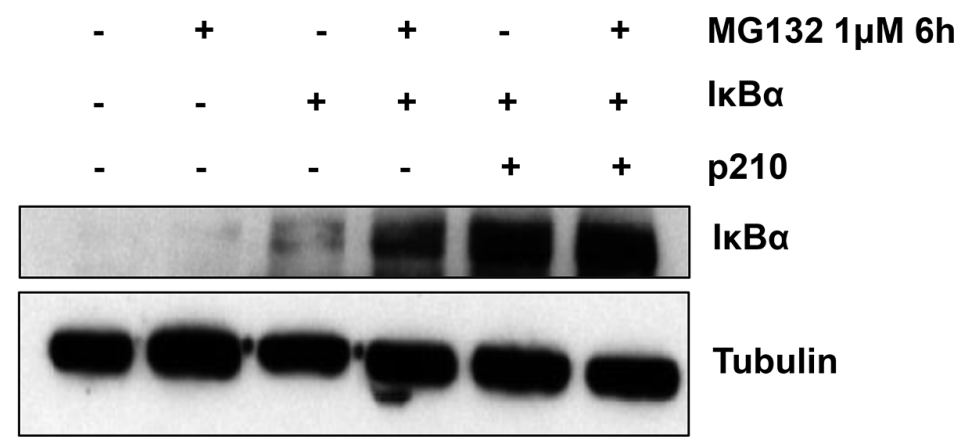

Figure 2: IкB $\alpha$ interactions and phosphorylation in BCR-ABL transfected cells. A. HEK293T cells were transfected with the indicated plasmids and assessed by immunoprecipitation with myc-tag antibody ( $\mathrm{I \kappa B} \alpha$ ) and western blot. B. BV173 lysates were

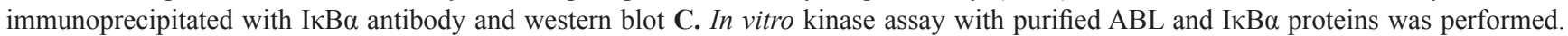
P-Tyr: phospho-tyrosine. D. qRT-PCR analysis of NFKBIA (IKB $\alpha$ ) performed on normal and CML bone marrow samples and on HEK293T BCR-ABL and empty vector transfected cells. E. BCR-ABL and IкB $\alpha$-transfected HEK293T cells were incubated for 6 hours with $1 \mu \mathrm{M}$ of MG132. Western blot analysis was performed to evaluate I $\mathrm{\kappa B} \alpha$ protein level. Tubulin was used as loading control. 

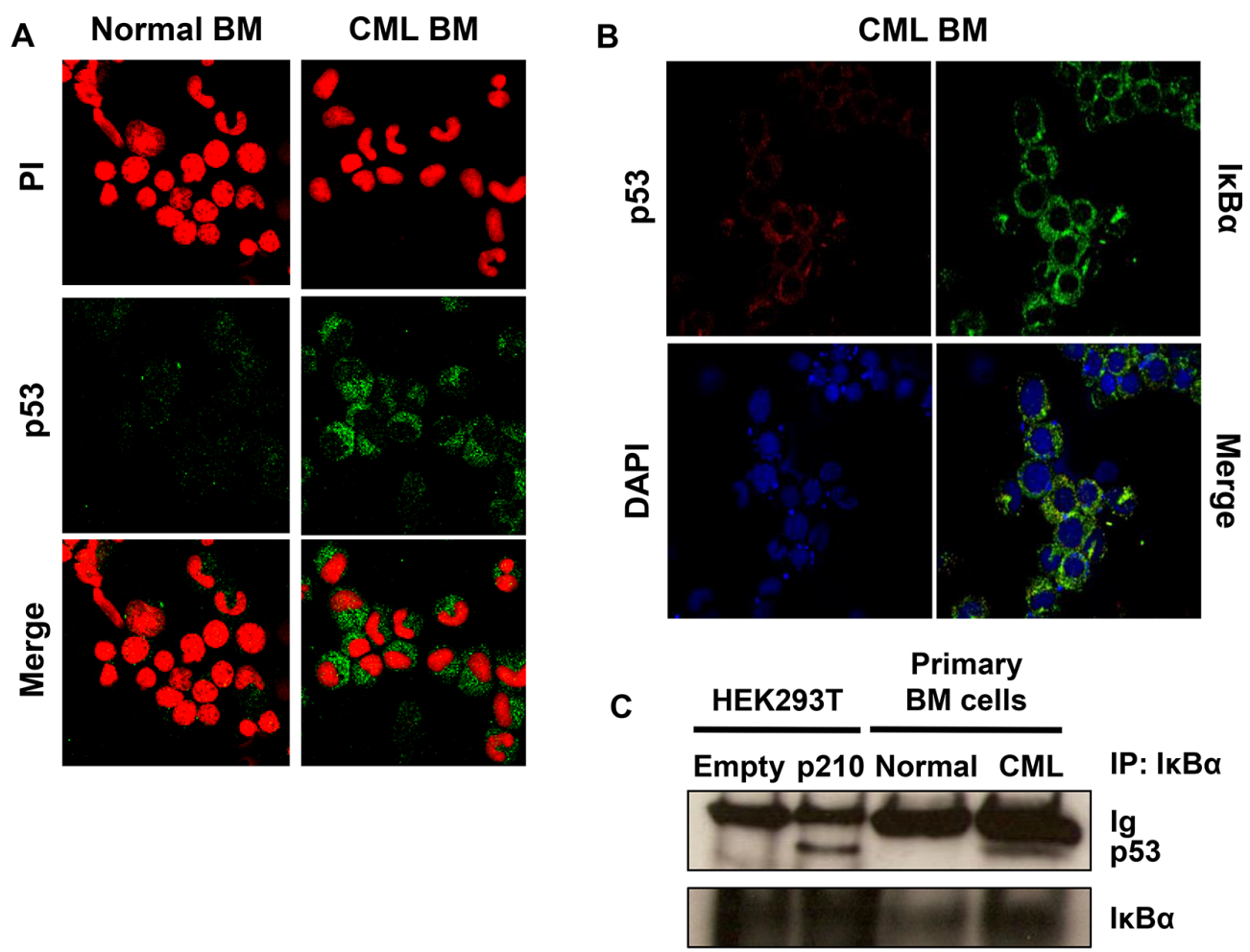

D

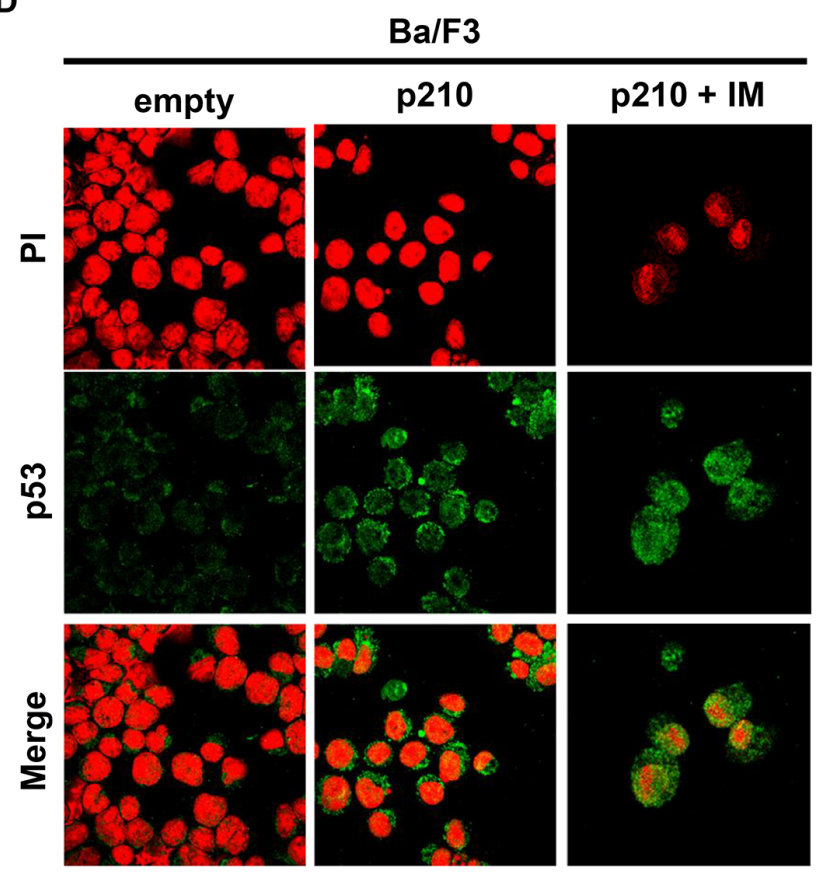

$\overline{\mathbf{X}}$
Q

$\frac{3}{\frac{1}{6}}$ . 

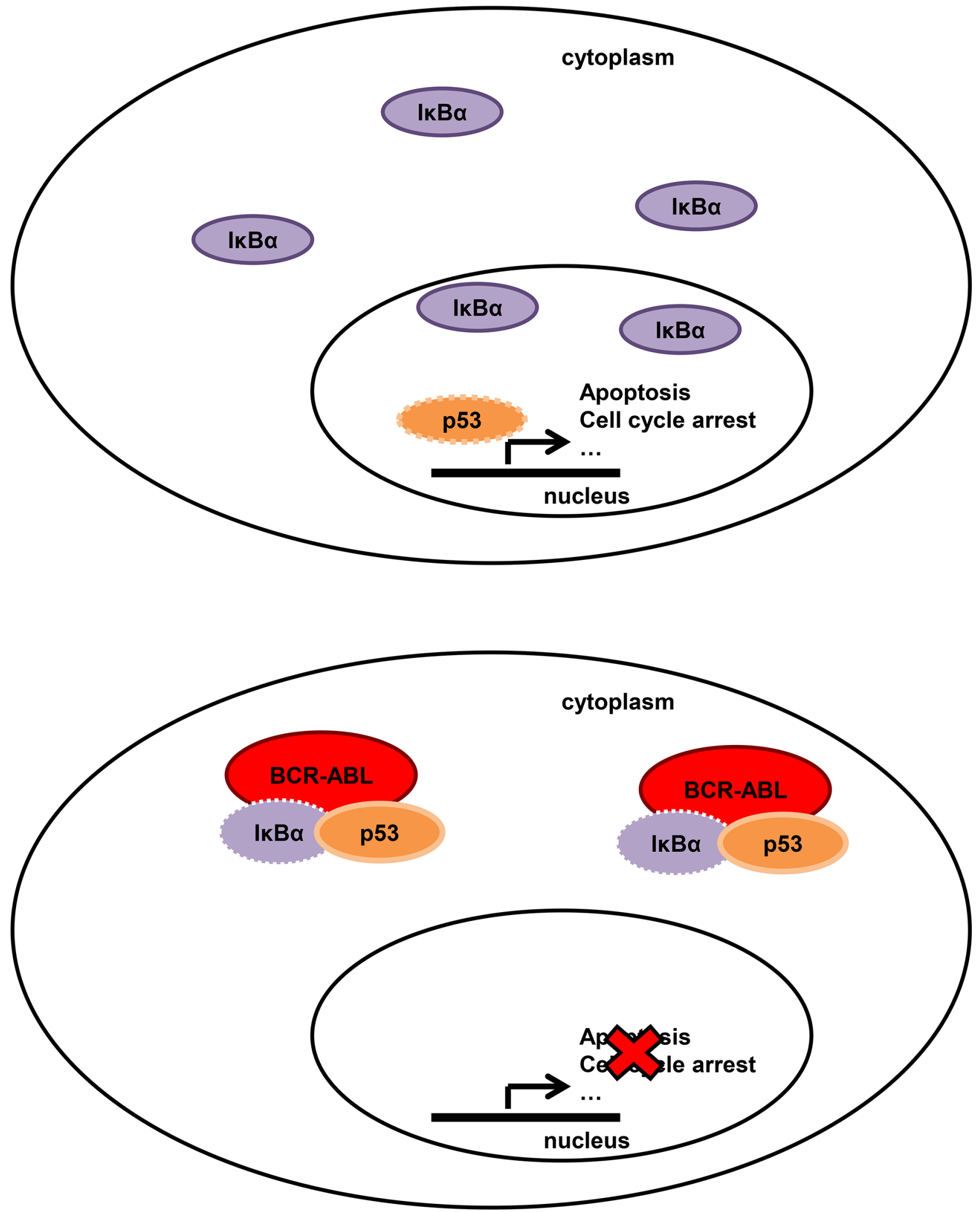

Figure 4: Model of BCR-ABL-IкBa-p53 network in normal (upper panel) and BCR-ABL positive cells (bottom panel). In normal cells I $\mathrm{KB} \alpha$ can shuttle from the cytoplasm to the nucleus to remove NF- $\mathrm{kB}$ and $\mathrm{p} 53$ from the DNA. In BCR-ABL positive cells, IKB $\alpha$ is mostly cytoplasmic, interacts with BCR-ABL and with $\mathrm{p} 53$. The BCR-ABL/IkB $\alpha$ network enables $\mathrm{p} 53$ to translocate into the nucleus and therefore functionally inactivate its tumor suppressive functions. 
Importantly, imatinib promotes p53 relocalization into the nucleus (Figure 3D) and apoptosis/growth arrest induction (data not shown).

To better evaluate whether the delocalization of p53 is associated with impairment of its function, we measured p21 mRNA expression in CML samples. TP53 is indeed known to regulate p21 expression [36]. As shown in Figure 3E, p21 mRNA levels are markedly reduced in CML primary cells, compared to normal bone marrow while imatinib treatment promotes p21 levels restoration.

In summary, we have demonstrated that in Chronic Myeloid Leukemia BCR-ABL physically interacts with $\mathrm{I} \kappa \mathrm{B} \alpha$, promotes its cytoplasmic localization, and favors the maintenance of the I $\kappa \mathrm{B} \alpha / \mathrm{p} 53$ complex into the cytoplasm. As a consequence, BCR-ABL negatively regulates the pro-apoptotic and growth arrest potentials of p53 (Figure 4).

Our work leads to the following conclusions. Firstly, BCR-ABL-mediated tumorigenesis does not only depend on the direct activation of pathways involved in the regulation of cell growth and survival, but also on the ability of BCR-ABL to counteract pathways that suppress proliferation and survival. In line with these considerations, BCR-ABL was already shown to inactivate the tumor suppressors PP2A, PTEN and others [13, 15-17]. Here, we provide evidences that BCR-ABL/I $\kappa \mathrm{B} \alpha$ complex affects the tumor suppressive functions of $\mathrm{p} 53$.

Secondary, our work further highlights the relevance of the I $\mathrm{B} \alpha-\mathrm{p} 53$ complex in cancer biology. This interaction has been already described although the mechanisms of regulation and the biological relevance were almost unknown [30-32]. Our data suggest that $\mathrm{I} \kappa \mathrm{B} \alpha$ is able to orchestrate two essential factors in tumorigenesis. From one side $\mathrm{I} \kappa \mathrm{B} \alpha$ negatively regulates the NF- $\kappa$ B subunit $\mathrm{p} 65$ and from the other $\mathrm{p} 53$. Therefore, we suggest that oncogenes could switch the balance of this interaction, favoring inactivation of p53. However, our data could not completely explain the mechanisms of $\mathrm{I} \kappa \mathrm{B} \alpha-\mathrm{p} 53$ formation and regulation. In a previous report, the I $\kappa \mathrm{B} \alpha-\mathrm{p} 53$ complex is disrupted by treatment with the tyrosine kinase inhibitor straurosporine, suggesting that $\mathrm{I} \kappa \mathrm{B} \alpha-\mathrm{p} 53$ complex is regulated by tyrosine kinases. Imatinib is also able to promote I $\mathrm{B} \alpha \alpha-\mathrm{p} 53$ disruption downstream of BCR-ABL, although we did not observe a direct $\mathrm{I} \kappa \mathrm{B} \alpha$ tyrosine phosphorylation by BCR-ABL. We therefore speculate that other kinases, downstream of $\mathrm{BCR}-\mathrm{ABL}$, or BCR-ABL kinase independent pathways, could be involved in the formation and regulation of the IкB $\alpha$-p53 complex.

Finally, our data imply that the BCR-ABL/I $\kappa \mathrm{B} \alpha /$ p53 network harbors therapeutic implications. Storing an active and genetically wild-type tumor suppressor could indeed offer the chance to design therapies to reactivate p53 with dramatic cancer selective apoptosis induction.

\section{MATERIALS AND METHODS}

\section{Cells, primary human samples and pharmacological treatments}

HEK293T, HeLa, K562, BV173 cells were obtained from ATCC and cultured according to vendor. Parental $\mathrm{Ba} /$ F3 and Ba/F3 p210 BCR-ABL were previously reported [19]. Twenty primary chronic phase CML and three normal bone marrow samples were collected at the San Luigi Hospital (Orbassano, Italy) with informed consent of patients at the time of diagnosis. Project was reviewed by the institutional Ethical Committee (code \#10/2013). Cell lines were incubated with $10 \mu \mathrm{M}$ Imatinib mesylate (Novartis) for 6 hours and with $1 \mu \mathrm{M}$ MG132 (Selleckchem) for 6 hours.

\section{Plasmids and transfection}

NFאBIA plasmid [20] was cloned into myctagged pRK5 plasmid [15]. BCR-ABL vector was described elsewhere [15]. BCR vector was cloned in pcDNA3.1 plasmid. Transient transfection was performed with X-treme GeneHP (Roche) reagent according to manufacturer's protocol.

\section{Western immunoblot and immunoprecipitation}

Proteins were extracted with a buffer containing 150 mM NaCl, 1 mM EDTA, 50 mM HEPES (pH 7.5), 1\% Triton X-100 and 10\% glycerol. For immunoprecipitations, lysates were precleared with normal mouse IgG antibody (Santa Cruz, \#2025) or normal rabbit IgG (Santa Cruz, \#2027)and Protein A/G-PLUS-Agarose (Santa Cruz, \# sc-2002) for 1 hour. Then lysates were incubated with antibody overnight at $4^{\circ} \mathrm{C}$ on a rotator. Protein A/G-PLUSAgarose beads were added and incubated for 2 hours at $4^{\circ} \mathrm{C}$ with rotation. Agarose beads bound with immunoreactive complexes were washed four times with cold co-IP buffer. Following the final wash, immunoprecipitated complexes were eluted with $30 \mu \mathrm{l}$ of $2 \mathrm{x}$ sample buffer, boiled for $5 \mathrm{~min}$ and analyzed using SDS-PAGE. Equal amounts of proteins were denatured in Laemmli sample buffer at $95^{\circ} \mathrm{C}$ for $5 \mathrm{~min}$, resolved by SDS-PAGE on $8 \%$ gels and subsequently transferred to a nitrocellulose membrane. Immunoblotting was carried out using antibodies against $\mathrm{I} \kappa \mathrm{B} \alpha$ (Cell signaling \#4814), myc-tag (Cell signaling \#2276), p53 (Santa Cruz sc-98), Bcr (Cell signaling \#3902), P-Tyr (Santa Cruz sc-7020), c-Abl (Cell signaling \#2862). Blots were scanned into the ChemiDoc XRS+ system (Biorad) and image acquisition and analysis was performed using ImageLab software (Biorad).

\section{Kinase assay}

An in vitro kinase assay with purified full length ABL (Invitrogen, \#P3049) and IкB $\alpha$ (BIOMOL, UW9975) proteins was performed as previously described [15]. 


\section{Immunofluorescence and immunohistochemistry}

Immunofluorescence was performed by fixing cells with $4 \%$ PFA, permeabilizing them with $0.5 \%$ Triton X-100 and blocking with bovine serum albumin for 30 minutes. After blocking, cells were incubated with antibody at 1:100 at room temperature for 2 hours, followed by incubation with 1:500 secondary antibodies Alexa fluor-488 (Invitrogen \# A-11078) and Alexa fluor-543 (Invitrogen \# A-11030) at room temperature for 1 hour. Nuclei were stained with propidium iodide or DAPI for 5 minutes. Immunohistochemistry experiments were performed on formalin-fixed, paraffin-embedded tissues using anti-IкB $\alpha$ antibody (Cell Signaling, \#4814) according to manufacturer's protocols.

\section{Real-time quantitative polymerase chain reaction}

Total RNA was extracted using standard procedures. Quantitative Real-Time PCR (qRT-PCR) reactions and fluorescence measurements were performed using the 7300 RealTime PCR System (Applied Biosystem). For NFKBIA and $\mathrm{p} 21$ quantification, specific assays with ondemand primer/probe kits (assay ID 00355671_g1 for NFKBIA, Hs00355782 m1 for $\mathrm{p} 21$ and Hs00245445 m1 for ABL1) (Applied Biosystems, Foster City, CA, USA) were conducted according to the manufacturer's instructions. The NFKBIA and p21 Ct obtained by qRTPCR was normalized with respect to the $\mathrm{Ct}$ of $\mathrm{ABL}$ and expressed as $2-\Delta \Delta \mathrm{Ct}$. Universal Human Reference RNA (Stratagene, \#740000) was used to calibrate the assay.

\section{Statistical analysis}

Statistical analysis was performed with GraphPad Prism v5.0d (GraphPad Software), using the Student t test. Significance was set at $P<0.05$.

\section{ACKNOWLEDGMENTS}

We thank all members of Prof. Saglio's laboratory and clinical division of hematology for comments and discussion. This work was supported by 2011 Giovani Ricercatori - Ricerca Finalizzata, Ministero Salute to A.M. and AIRC grant to G.S.

\section{Author contributions}

The experiments were conceived, designed and performed by A.M., C.P., S.C, and G.C. Bone marrow immunohistochemistry was performed by U.F. and M.P. RNA extraction from patients' bone marrow samples was performed by A.V, F.C and E.G. S.R. and R.P. generated and provided cell lines. Data and manuscript were reviewed by G.S., D.T, R.T. and A.G. The paper was written by S.C. and A.M.

\section{CONFLICTS OF INTEREST}

The authors have no conflict of interest to declare.

\section{REFERENCES}

1. Knudson AG. Mutation and cancer: statistical study of retinoblastoma. Proc Natl Acad Sci U S A. 1971; 68:820-823.

2. Berger AH, Knudson AG, Pandolfi PP. A continuum model for tumour suppression. Nature. 2011; 476:163-169.

3. Leslie NR, Foti M. Non-genomic loss of PTEN function in cancer: not in my genes. Trends Pharmacol Sci. 2011; 32:131-140.

4. Correia NC, Gírio A, Antunes I, Martins LR, Barata JT. The multiple layers of non-genetic regulation of PTEN tumour suppressor activity. Eur J Cancer Oxf Engl 1990. 2014; 50:216-225.

5. Ren R. Mechanisms of BCR-ABL in the pathogenesis of chronic myelogenous leukaemia. Nat Rev Cancer. 2005; 5:172-183.

6. Saglio G, Morotti A, Mattioli G, Messa E, Giugliano E, Volpe $\mathrm{G}$, et al. Rational approaches to the design of therapeutics targeting molecular markers: the case of chronic myelogenous leukemia. Ann N Y Acad Sci. 2004; 1028:423-431.

7. Morotti A, Panuzzo C, Fava C, Saglio G. Kinase-inhibitorinsensitive cancer stem cells in chronic myeloid leukemia. Expert Opin Biol Ther. 2014; 14:287-299.

8. Apperley JF. Chronic myeloid leukaemia. Lancet Lond Engl. 2015; 385:1447-1459.

9. Chereda B, Melo JV. Natural course and biology of CML. Ann Hematol. 2015; 94:S107-121.

10. Pellicano F, Mukherjee L, Holyoake TL. Concise review: cancer cells escape from oncogene addiction: understanding the mechanisms behind treatment failure for more effective targeting. Stem Cells Dayt Ohio. 2014; 32:1373-1379.

11. Melo JV, Barnes DJ. Chronic myeloid leukaemia as a model of disease evolution in human cancer. Nat Rev Cancer. 2007; 7:441-453.

12. Pear WS, Miller JP, Xu L, Pui JC, Soffer B, Quackenbush RC, et al. Efficient and rapid induction of a chronic myelogenous leukemia-like myeloproliferative disease in mice receiving P210 bcr/abl-transduced bone marrow. Blood. 1998; 92:3780-3792.

13. Neviani P, Harb JG, Oaks JJ, Santhanam R, Walker CJ, Ellis JJ, et al. PP2A-activating drugs selectively eradicate TKI-resistant chronic myeloid leukemic stem cells. J Clin Invest. 2013; 123:4144-4157.

14. Peng $\mathrm{C}$, Chen $\mathrm{Y}$, Yang $\mathrm{Z}$, Zhang $\mathrm{H}$, Osterby L, Rosmarin AG, et al. PTEN is a tumor suppressor in CML stem cells and BCR-ABL-induced leukemias in mice. Blood. 2010; 115:626-635. 
15. Morotti A, Panuzzo C, Crivellaro S, Pergolizzi B, Familiari U, Berger AH, et al. BCR-ABL disrupts PTEN nuclear-cytoplasmic shuttling through phosphorylation-dependent activation of HAUSP. Leukemia. 2014; 28:1326-1333.

16. Morotti A, Panuzzo C, Crivellaro S, Carrà G, Fava C, Guerrasio A, et al. BCR-ABL inactivates cytosolic PTEN through Casein Kinase II mediated tail phosphorylation. Cell Cycle Georget Tex. 2015; 14:973-979.

17. Panuzzo C, Crivellaro S, Carrà G, Guerrasio A, Saglio G, Morotti A. BCR-ABL promotes PTEN downregulation in chronic myeloid leukemia. PloS One. 2014; 9:e110682.

18. Huang F-F, Zhang L, Wu D-S, Yuan X-Y, Chen F-P, Zeng $\mathrm{H}$, et al. PTEN regulates BCRP/ABCG2 and the side population through the PI3K/Akt pathway in chronic myeloid leukemia. PloS One. 2014; 9:e88298.

19. Redaelli S, Mologni L, Rostagno R, Piazza R, Magistroni V, Ceccon $\mathrm{M}$, et al. Three novel patient-derived BCR/ABL mutants show different sensitivity to second and third generation tyrosine kinase inhibitors. Am J Hematol. 2012; 87:E125-128.

20. Müller M, Morotti A, Ponzetto C. Activation of NF-kappaB is essential for hepatocyte growth factor-mediated proliferation and tubulogenesis. Mol Cell Biol. 2002; 22:1060-1072.

21. Perkins ND. The diverse and complex roles of NF- $\kappa$ B subunits in cancer. Nat Rev Cancer. 2012; 12:121-132.

22. Panwalkar A, Verstovsek S, Giles F. Nuclear factor-kappaB modulation as a therapeutic approach in hematologic malignancies. Cancer. 2004; 100:1578-1589.

23. Reuther JY, Reuther GW, Cortez D, Pendergast AM, Baldwin AS. A requirement for NF-kappaB activation in BcrAbl-mediated transformation. Genes Dev. 1998; 12:968-981.

24. Kirchner D, Duyster J, Ottmann O, Schmid RM, Bergmann L, Munzert G. Mechanisms of Bcr-Ablmediated NF-kappaB/Rel activation. Exp Hematol. 2003; 31:504-511.

25. Morotti A, Cilloni D, Pautasso M, Messa F, Arruga F, Defilippi I, et al. NF-kB inhibition as a strategy to enhance etoposide-induced apoptosis in K562 cell line. Am J Hematol. 2006; 81:938-945.
26. Cilloni D, Messa F, Arruga F, Defilippi I, Morotti A, Messa E, et al. The NF-kappaB pathway blockade by the IKK inhibitor PS1145 can overcome imatinib resistance. Leukemia. 2006; 20:61-67.

27. Hsieh M-Y, Van Etten RA. IKK-dependent activation of NF- $\kappa \mathrm{B}$ contributes to myeloid and lymphoid leukemogenesis by BCR-ABL1. Blood. 2014; 123:2401-2411.

28. Gallipoli P, Pellicano F, Morrison H, Laidlaw K, Allan EK, Bhatia R, et al. Autocrine TNF- $\alpha$ production supports CML stem and progenitor cell survival and enhances their proliferation. Blood. 2013; 122:3335-3339.

29. Lounnas N, Frelin C, Gonthier N, Colosetti P, Sirvent A, Cassuto J-P, et al. NF-kappaB inhibition triggers death of imatinib-sensitive and imatinib-resistant chronic myeloid leukemia cells including T315I Bcr-Abl mutants. Int J Cancer J Int Cancer. 2009; 125:308-317.

30. Chang N-S. The non-ankyrin C terminus of Ikappa Balpha physically interacts with $\mathrm{p} 53$ in vivo and dissociates in response to apoptotic stress, hypoxia, DNA damage, and transforming growth factor-beta 1-mediated growth suppression. J Biol Chem. 2002; 277:10323-10331.

31. Dreyfus DH, Nagasawa M, Gelfand EW, Ghoda LY. Modulation of p53 activity by IkappaBalpha: evidence suggesting a common phylogeny between NF-kappaB and p53 transcription factors. BMC Immunol. 2005; 6:12.

32. Li X, Xing D, Wang J, Zhu D-B, Zhang L, Chen X-J, et al. Effects of IkappaBalpha and its mutants on NF-kappaB and p53 signaling pathways. World J Gastroenterol WJG. 2006; 12:6658-6664.

33. Bieging KT, Mello SS, Attardi LD. Unravelling mechanisms of p53-mediated tumour suppression. Nat Rev Cancer. 2014; 14:359-370.

34. Brosh R, Rotter V. When mutants gain new powers: news from the mutant p53 field. Nat Rev Cancer. 2009; 9:701-713.

35. Calabretta B, Perrotti D. The biology of CML blast crisis. Blood. 2004; 103:4010-4022.

36. Warfel NA, El-Deiry WS. p21WAF1 and tumourigenesis: 20 years after. Curr Opin Oncol. 2013; 25:52-58. 